\title{
FDA Memorandum of Understanding
}

National Cancer Institute

\section{Source}

National Cancer Institute. FDA Memorandum of Understanding. NCI Thesaurus. Code C142553.

A formal document outlining an agreement between the US Food and Drug Administration and another entity. 